\title{
Decreased Time on the Nondominant One- Leg Standing Test Associated with Repeated Falls in Older Residents with Healthy Aging, Mild Cognitive Impairment, and Dementia: The Wakuya Project
}

\author{
Keiichi Kumai ${ }^{a}$ Mika Kumaib, c Junko Takada ${ }^{a}$ Jiro Oonuma ${ }^{a}$ Kei Nakamura ${ }^{a}$ \\ Kenichi Meguroa, b, d \\ ${ }^{a}$ Geriatric Behavioral Neurology Project, Tohoku University New Industry Creation Hatchery Center, Sendai, Japan;

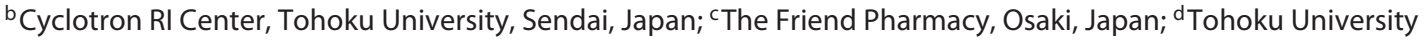 \\ Graduate School of Medicine, Sendai, Japan
}

\section{Keywords}

Older adults/people/persons - Mild cognitive impairment . Nondominant leg $\cdot$ One-leg standing $\cdot$ Repeated falls

\begin{abstract}
Introduction: The aim of this study is to clarify the association between repeated falls and the dominant/nondominant side in the open-eyed one-leg standing (OLS) test among people who are healthy or have mild cognitive impairment $(\mathrm{MCl})$ or dementia in a community setting. We recruited 180 participants from 39 areas in the town of Wakuya. Methods: This is a cross-sectional study. Participants were classified into 3 Clinical Dementia Rating (CDR) groups, i.e., CDR 0 (healthy, $n=71)$, CDR $0.5(\mathrm{MCl}, n=85)$, and CDR $1+$ $(n=23)$, and they were investigated for motor function (grip strength, 6-m normal gait speed, timed up and go test, and OLS test) and falls during the past year. Results: Subjects with a CDR of 0.5 had higher rates of single and repeated falls (13.0 and 23.4\%, respectively) than the CDR 0 group (12.1 and $4.5 \%$, respectively), as did those in CDR $1+$ group (15.0 and $30.0 \%$ ). For the CDR 0.5 group, the frequency of falls was
\end{abstract}

karger@karger.com www.karger.com/dee

Karger ${ }^{\prime \prime} \div$

BOPEN ACCESS
(C) 2021 The Author(s)

Published by S. Karger AG, Basel

This is an Open Access article licensed under the Creative Commons Attribution-NonCommercial-4.0 International License (CC BY-NC) (http://www.karger.com/Services/OpenAccessLicense), applicable to the online version of the article only. Usage and distribution for commercial purposes requires written permission. negatively (biologically meaningful direction) correlated with the left OLS time. No significant correlations with falls were found for other motor function tests. Another analysis separating the CDR 0.5 group into 2 subgroups (repeated falls vs. no or a single fall) also showed that the left OLS time was lower in subjects with repeated falls. Conclusion: People with $\mathrm{MCl}$ who had fallen repeatedly in the year before the assessment had a significantly lower left OLS time compared to those who had not fallen or had had 1 fall with $\mathrm{MCl}$. None of the other physical measures were associated with past repeat falls including OLS on the dominant right side. No such findings were noted in the CDR 0 and CDR $0+$ groups.

(c) 2021 The Author(s)

Published by S. Karger AG, Basel

\section{Introduction}

People can learn from accidents and change behaviors to avoid repeating accidents thereafter. However, people with cognitive impairment may repeat the same accidents. People may occasionally fall but should avoid re- 
peating falls that can lead to adverse events, such as fractures [1-3]. Previously, people with a Clinical Dementia Rating (CDR) $[4,5]$ of 0.5 (mild cognitive impairment; MCI) were found to show learning disabilities neuropsychologically [6]. Thus, we have herein paid attention to "repeated falls" and not simply to "a single fall."

Repeated falls leading to a femoral neck fracture are not only associated with a substantial loss of functional independence but also adversely affect the rehabilitation outcomes of patients with a fracture [7].

Falls are the main cause of fractures [1], resulting in a decreased quality of life for older adults [8]. Quite a few older people suffer falls each year resulting in major injuries such as fractures [9], and thus early detection of older people who are at risk is important, as is the implementation of possible interventions that may preserve their quality of life.

The major risk factors for falls in older adults include gait and/or balance disturbances and muscle weakness [9]. Disturbed balance and motor function tests such as walking speed, grip strength, performance on the timed up and go test (TUG), and walking aid use have been reported to be associated with the risk of falls $[10,11]$.

In addition to these findings, cognitive impairment, MCI [12], and dementia [13, 14] are associated with falls. Several studies have found that cognitive impairment, especially with regard to processing speed or executive function, is related to falls in older adults [15-18], especially people with MCI; moreover, it has been reported that combined physical and cognitive impairments predict falls better than physical or cognitive impairment alone [19].

Since there are so many older adults who are assessed as having a CDR of 0.5 (MCI) in the community [20], and who show impaired executive functions [21], it is necessary to use a quick, easily understandable method to predict falls.

In this aspect, we have focused on the one-leg standing (OLS) test. It is a simple test that measures the elapsed time standing on one-leg with no support and does not require a large space or any apparatus. According to previous reports, the OLS test is a strong predictor of falls $[22,23]$.

However, the relationship between the OLS test and falls is still unclear, and positive $[14,24,25]$ and negative $[26,27]$ findings have been reported. This is probably due to the use of different methods. Most OLS tests are performed with the participants having their eyes open [28, 29]. Regarding the choice of leg, Netz and Argov [30] recommended the use of both legs, since they found large differences depending on the leg used. However, other studies have found no differences between legs [27, 31]. The maximum OLS time used for measurement has been 15 [32], 30 [27], 45 [33], 60 [30] and $\geq 60 \mathrm{~s}$ [34, 35], and the frequency of measurement has varied from 1 to 5 times [36], or the best time [27] or the average time from several trials [37] has been used. We used $120 \mathrm{~s}$ as our measurement time (see below).

Therefore, the aim of this study is to clarify the associations between repeated falls and the dominant/nondominant side in the OLS test in healthy people and in those with MCI and dementia in a community setting.

\section{Methods}

\section{The Wakuya Project}

This study was performed in the town of Wakuya, which is in an agricultural area in the Miyagi Prefecture, in Northern Japan. The population is 16,485 , including 2,907 older residents aged $\geq 75$ years in 2018. The aim of the Wakuya Project is to investigate physical activity and the association between life style-related diseases and cognitive function in older residents. The number of participants was chosen to give a significant $95 \%$ CI with the assumption of a prevalence of dementia of $10-15 \%$.

\section{Participants}

A total of 180 participants from 39 areas in Wakuya were recruited, including 80 from 4 areas with low official medical checkup rates and 100 from 13 areas with high medical check-up rates to minimize the effects of the check-up. All of the subjects were right-handed; however, we cannot rule out the possibility that some were born left-handed but were forced to be right-handed in childhood due to sociocultural pressures in the area. The subjects underwent neuropsychological, motor function, and physical examinations, and family members were interviewed about the daily life of each subject, including falls. The severity of dementia was evaluated in a CDR decision conference. People with the following conditions were excluded: (1) paralysis causing severe motility disability (paralysis was defined by the presence of neurological symptoms and significant differences in muscular strength between the left and right arms or legs by measuring the muscular strength of the hands), (2) ataxia due to cerebral or vestibular diseases diagnosed by a neurologist or an otorhinolaryngologist, and (3) an orthopedic disease, diagnosed by an orthopedist, that could affect motor tasks.

Also, public health nurses in the town confirmed the absence of illnesses such as Meniere disease and musculoskeletal disease with reference to physicians' records.

\section{Ethics}

An explanation related of this study was given in public halls. After obtaining written consent from each participant, public health nurses visited the participant's home on another day to obtain consent from family members. 
Table 1. Demographics of the participants

\begin{tabular}{|c|c|c|c|c|c|}
\hline & CDR 0 & CDR 0.5 & CDR $1+$ & $\chi^{2} / F$ value & $p$ value \\
\hline Subjects (men/women), $n$ & $72(23 / 49)$ & $85(39 / 46)$ & $23(12 / 11)$ & 4.46 & 0.107 \\
\hline Age, years & $79.6(3.6)$ & $80.2(3.9)$ & $83.0(4.2)^{\mathrm{ab}}$ & 6.99 & 0.001 \\
\hline Education, years & $11.3(2.2)$ & $10.6(2.4)$ & $9.5(2.5)^{\mathrm{a}}$ & 5.16 & 0.007 \\
\hline MMSE score & $26.0(2.5)$ & $23.6(3.1)^{\mathrm{a}}$ & $19.5(3.6)^{\mathrm{ab}}$ & 43.42 & 0.000 \\
\hline
\end{tabular}

Data are shown as means (SD) unless otherwise stated. Gender did not differ significantly among the groups ( $\chi^{2}$ test). In a one-way ANOVA (Bonferroni post hoc test), age was significantly higher in the CDR $1+$ group $(F=6.993$; $p=0.001)$, years of education was significantly lower in the CDR $1+$ group than in the CDR 0 group $(F=5.161 ; p=0.007)$, and the MMSE score was significant in descending order as follows: CDR 0, CDR 0.5 , and CDR $1+$ groups $(F=43.420 ; p=0.000)$. ${ }^{\text {a }}$ Significant difference vs. The CDR 0 group $(p<0.05) .{ }^{\mathrm{b}}$ Significant difference vs. The CDR 0.5 group $(p<0.05)$.

\section{CDR Assessment}

A clinical team of medical doctors and public health nurses determined the CDR while blinded to the results of the Mini-Mental State Examination (MMSE). Before being interviewed by the doctors, the participants were visited in their homes by public health nurses for evaluation of their daily activities. Observations by the family with respect to the participants' lives were obtained using a semi-structured questionnaire. The participants were interviewed by doctors to assess episodic memory, orientation, and judgment. Finally, with reference to the information provided by the family and the public health nurses, the participants' CDR stage was decided at a joint meeting. A reliable Japanese version of the CDR Worksheet [5] was established, and dementia was diagnosed based on the Diagnostic and Statistical Manual of Mental Disorders (DSM)-IV criteria. One of the authors (K.M.) was certified as a CDR rater at the Alzheimer's Disease Research Center Memory and Aging Project of the Washington University School of Medicine. The CDR 0 (healthy), CDR 0.5 (MCI), and CDR 1+ (dementia) groups included 72,85 , and 23 participants, respectively. Dementia was also confirmed using the DSM-IV criteria.

Table 1 shows the demographics of the study population. Gender did not differ significantly among the CDR $0,0.5$, and $1+$ groups. The CDR 1+ group was older and had a lower education level, and lower MMSE scores than the other groups.

\section{Falls during the Past Year}

A fall is defined by the World Health Organization as an event that results in a person coming to rest inadvertently on the ground or floor or other lower level.

The families of the participants were interviewed about the participants' frequency of falls in the past year. The definition of the FICSIT examination (20:35) was used to define "fall". The frequency of falls per year was defined as follows: one or more as "presence of a fall" and zero as "absence of a fall." Repeated falls per year was defined as follows: 2 or more as "presence of repeated falls" and one or fewer as "absence of repeated falls."

\section{Motor Function Tests}

The following tests were performed under careful observation by a physical therapist (K.K.), with occasional resting time.

\section{Open-Eyed OLS Test}

After the participant was asked to "put both hands on the waist, raise one leg about $5 \mathrm{~cm}$ from the floor, and stand up for as long as possible," a practice test was performed once or twice. The actual test was then performed with the same instructions. The maximum time for standing up was $120 \mathrm{~s}$, and times for the left and right legs were each measured twice. The time was measured until a near fall due to strong swaying, shifting of the standing leg, or setting of the raised leg down on the floor. The average times of the 2 measurements for the dominant leg (right side; all of the participants were right-handed) and the nondominant leg (left side) were used in the analysis.

\section{Walking Speed Test}

A run-up path of $1.5 \mathrm{~m}$ was placed at the start and end of a 6-m walking track. After the request to "walk at your usual walking speed" was given, the time taken for the test was measured twice using a stopwatch. The average of the 2 measurements was used for the analysis.

\section{TUG Test}

A cone was placed $3 \mathrm{~m}$ from the front of a chair with a seat height of $40 \mathrm{~cm}$. After the participants were asked to "stand up from a sitting posture on the chair, turn back $3 \mathrm{~m}$ from the front of the marked point, and sit down again on the chair," the time taken from the sitting posture to sitting down again was measured. The participants walked at their usual walking speed after receiving an instruction to start the test. The time taken was measured twice using a stopwatch, and the average time of the 2 measurements was used.

\section{Grip Strength}

The width of the grip of a grip dynamometer was adjusted to bend perpendicularly at the second joint of the forefinger. The grip dynamometer was gripped in the direction outward from the indicator. The participants were instructed to "keep the grip dynamometer apart from your body and clothes and grip the grip dynamometer with all of your strength. Do not swing the grip dynamometer during gripping." The grip strengths of the left and right hands were alternately measured twice, and the average strength of the 2 measurements was used. 
Table 2. Frequency of falls and motor functions for each CDR group

\begin{tabular}{|c|c|c|c|c|c|c|c|c|c|}
\hline & \multicolumn{3}{|c|}{ CDR 0} & \multicolumn{3}{|c|}{ CDR 0.5} & \multicolumn{3}{|c|}{ CDR $1+$} \\
\hline & $n$ & $R_{\mathrm{s}}$ & $p$ value & $n$ & $R_{\mathrm{s}}$ & $p$ value & $n$ & $R_{\mathrm{s}}$ & $p$ value \\
\hline Left OLS time, s & 64 & -0.07 & 0.287 & 70 & $-0.30^{* *}$ & 0.005 & 19 & -0.34 & 0.079 \\
\hline Right OLS time, s & 63 & -0.17 & 0.093 & 70 & -0.14 & 0.117 & 19 & -0.04 & 0.438 \\
\hline Walking speed, $\mathrm{m} / \mathrm{s}$ & 64 & -0.01 & 0.471 & 73 & -0.25 & 0.018 & 20 & -0.12 & 0.314 \\
\hline TUG test time, s & 63 & 0.11 & 0.186 & 73 & 0.15 & 0.097 & 19 & 0.10 & 0.348 \\
\hline Left grip, kg & 65 & -0.16 & 0.099 & 73 & -0.23 & 0.026 & 20 & -0.27 & 0.130 \\
\hline Right grip, kg & 65 & -0.09 & 0.234 & 73 & -0.25 & 0.016 & 20 & -0.14 & 0.284 \\
\hline
\end{tabular}

Shown are the Spearman rank correlation coefficients between the frequency of falls and the OLS time and various motor functions in each CDR group. There was only a significant correlation between the frequency of falls and the left OLS time in the CDR 0.5 group.

\section{Analyses}

Since people with cognitive impairment may repeat the same accidents, we focused on repeated falls, especially in subjects with MCI and dementia (CDR 0.5 or greater; i.e., CDR $0.5+$ ).

Analysis 1: Single and Repeated Falls for Each CDR Group

Association between CDR groups and falls were analyzed using a $\chi^{2}$ test and ANCOVA.

Analysis 2: Frequency of Falls and Various Motor Functions for Each CDR Group

Spearman rank correlation coefficient analysis was used to analyze associations between various motor functions and the frequency of falls.

Analysis 3: Repeated Falls and Motor Functions for the CDR $0.5+$ Group

The CDR 0.5+ group was classified into no or a single fall and repeated falls subgroups. Differences between these subgroups were analyzed using multiple ANCOVA with motor functions as dependent variables and age and gender as covariates.

\section{Results}

Figure 1 shows data for single and repeated falls in each CDR group. A $\chi^{2}$ test and ANCOVA showed a significant difference in repeated falls in the past year among the groups. A post hoc test showed significant differences between the CDR 0 and CDR 0.5 groups and between the CDR 0.5 and CDR $1+$ groups.

Table 2 summarizes the Spearman rank correlation coefficients between the frequency of falls and the left OLS time and various motor functions for each CDR group. There was a significant correlation between the frequency of falls and the left OLS time only in the CDR 0.5 group.

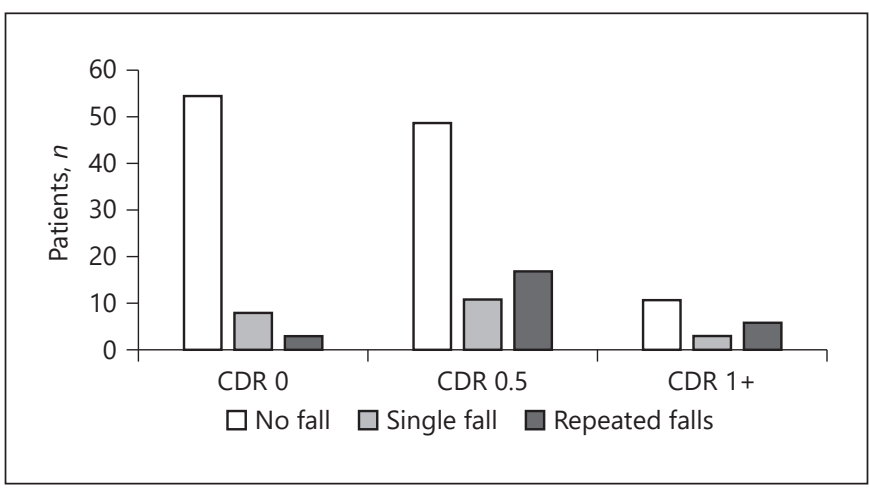

Fig. 1. Prevalence of past falls (none, single, or repeated) by cognitive group (healthy, MCI, and dementia). Single and repeated falls in each CDR group. A $\chi^{2}$ test showed a significant difference in repeated falls in the past year among CDR groups (value: 11.624; $p=0.003$ ). ANCOVA with presence of repeated falls as the dependent variable, the 3 CDR groups as fixed factors, and age and sex as covariates also showed a significant difference in repeated falls among the 3 CDR groups $(F=5.65 ; p=0.004)$. However, there were no significant differences in age or sex among the groups. Post hoc tests showed significant differences between the CDR 0 and CDR 0.5 groups and between the CDR 0.5 and CDR $1+$ groups.

As shown in Table 3, the left OLS time only had a significantly lower value in the repeated falls subgroup compared with the no or single fall subgroup.

\section{Discussion}

\section{Limitations}

Before discussing the results, we should mention some limitations of this study. First, the sample size (particularly subjects with dementia), was small, resulting in the 
Table 3. Repeated falls and motor functions for the CDR $0.5+$ group

\begin{tabular}{|c|c|c|c|c|c|c|}
\hline Right OLS time, s & $14.1(2.4)$ & $10.3(4.4)$ & 0.58 & 0.450 & 0.001 & 0.754 \\
\hline Walking speed, $\mathrm{m} / \mathrm{s}$ & $1.17(0.03)$ & $1.07(0.06)$ & 2.38 & 0.127 & 0.000 & 0.013 \\
\hline Right grip, kg & $22.0(0.7)$ & $21.2(1.2)$ & 0.34 & 0.562 & 0.002 & 0.000 \\
\hline
\end{tabular}

Values are presented as means (SE). A multiple ANOVA was done, with various motor functions as dependent variables, the presence of repeated falls as a fixed factor, and age and sex as covariants. The left OLS time in the various motor functions showed a significant difference with the presence of repeated falls $(F=4.491 ; p<0.05) .{ }^{*} p<0.05$.

prediction of very few events. Also, an analysis based on the CDR 0 group versus the 0.5 group versus the $1+$ group, together with nonfallers versus the single fallers versus the repeated fallers, needs a $3 \times 3$ ANCOVA. Unfortunately, the sample size was small. Further investigations would be needed to clarify these points. Second, although the muscle strength of the legs of all of the participants was neurologically (manually) examined by a neurologist, we did not take objective measures to assess it. This is a community-based study, and we had a time limitation.

\section{Falls of MCI and Dementia}

The results of this study showed that the CDR 0.5 and CDR $1+$ groups had higher rates of single and repeated falls compared to the CDR 0 group. For the CDR 0.5 group, the frequency of falls was negatively (biologically meaningful direction) correlated with the left OLS time. Another analysis separating the CDR 0.5 group into 2 subgroups (repeated falls vs. no or a single fall) showed that the left OLS time was shorter in subjects with repeated falls. Since falls increased with higher CDR scores, these results support previous findings that MCI and dementia are risk factors for a fall $[13,38,39]$.

As earlier described, people can learn from accidents and change behaviors to avoid repeating accidents thereafter. However, people with cognitive impairment may repeat the same accidents. People may occasionally fall but should avoid repeating falls that can lead to adverse events, such as fractures. Previously, people with a CDR of 0.5 (MCI) were found to show learning disabilities neuropsychologically. Herein, we found that people with MCI or dementia cannot learn from the first accident to avoid a second accident, and their family or caregiver should pay attention in case of repeated accidents, even after having instructed them.

Some of the patients and older residents in the community stated that, "falling means the end." Clearly, few people want to experience a fall; therefore, people will try to avoid falling if they fall once. If people fall repeatedly, MCI and dementia, and hidden illnesses such as Meniere disease and musculoskeletal disease, may be present; thus, it is important to observe the occurrence of repeated falls. There is also an association between an increased frequency of falls and increased femoral neck fractures, and this also indicates that the frequency of falls and the occurrence of repeated falls are more important than just a single fall.

\section{Nondominant OLS Test}

It was of interest that repeated falls only showed an association with the nondominant OLS time. Only left OLS showed any association with repeated falls in the CDR $0.5+$ group; thus, there may be an association of repeated falls with a decreased OLS time on the nondominant side in people aged $\geq 75$ years. This suggests that the nondominant OLS test may be able to detect CDR 0.5 subjects with a higher risk of falls.

The nondominant side may be important because right-handed people tend to start from the right foot in daily activities such as walking and climbing stairs and in sprints and marathons. With respect to body mechanics, performing an activity with the left leg as the pivot leg is easy for right-handed people. Falls happen due to motor and cognitive decline, drugs, and medical disorders such as dizziness, epilepsy, and stroke. Partial weakening of 
support from the nondominant side, i.e., the pivot leg, due to muscle weakness and performance function disabilities as a result of aging among CDR $0.5+$ subjects aged $\geq 75$ years may also increase the possibility of a fall.

\section{Conclusions}

Our results show that a simple OLS test using the nondominant side can identify the risk of a fall. In the community, public health nurses can perform this test for early detection of people at risk for a fall. The test can also contribute to monitoring of treatment after a fall and to prevention of repeated falls.

\section{Acknowledgment}

We are grateful to all of the staff in Wakuya, especially the public health nurses, and the staff of the Geriatric Behavioral Neurology Project, Tohoku University New Industry Creation Hatchery Center (NICHe). We also thank Ms. Keiko Chida, Yuriko Kato, and Megumi Kano.

\section{Statement of Ethics}

Written informed consent was obtained from each of the participants and their families. This study was approved by the ethics committees of the Wakuya government and the Tohoku University Graduate School of Medicine (2014-1-565).

\section{Conflict of Interest Statement}

The authors have no conflict of interests to declare.

\section{Funding Sources}

This work was supported by the Commissioned Research Fund of the City of Wakuya.

\section{Author Contributions}

K.K.: data analysis and writing of this paper. K.M.: design, direction, and writing of this paper. M.K., J.T., J.O., and K.N.: data collection.

\section{References}

1 Baidwan NK, Naranje SM. Epidemiology and recent trends of geriatric fractures presenting to the emergency department for United States population from year 2004-2014. Public Health. 2017 Jan;142:64-9.

2 Hagino H, Sakamoto K, Harada A, Nakamura T, Mutoh Y, Mori S, et al. Committee on osteoporosis of the Japanese Orthopedic Association. Nationwide one-decade survey of hip fractures in Japan. J Ortho Sci. 2010;15(6):737-45.

3 Schwartz AV, Nevitt MC, Brown BW Jr, Kelsey JL. Increased falling as a risk factor for fracture among older women: the study of osteoporotic fractures. Am J Epidemiol. 2005 Jan;161(2):180-5.

4 Morris JC. The Clinical Dementia Rating (CDR): current version and scoring rules. Neurology. 1993 Nov;43(11):2412-4.

5 Meguro K. A clinical approach of dementia: An instruction of CDR worksheet. Tokyo: Igaku-Shoin; 2004. pp. 75-88. [Japanese].

6 Kasai M, Meguro K, Hashimoto R, Ishizaki J, Yamadori A, Mori E. Non-verbal learning is impaired in very mild Alzheimer's disease (CDR 0.5): normative data from the learning version of the Rey-Osterrieth Complex Figure Test. Psychiatry Clin Neurosci. 2006 Apr;60(2):139-46.

7 Aizen E, Nixon H, Shugaev I. Awareness and functional outcome of hip fracture-related falls among patients with a history of recurrent falling. Isr Med Assoc J. 2018 Jan;20(1):38-42.
8 Kannus $\mathrm{P}$, Sievänen $\mathrm{H}$, Palvanen M, Järvinen T, Parkkari J. Prevention of falls and consequent injuries in elderly people. Lancet. 2005 Nov;366(9500):1885-93.

9 Tinetti ME, Kumar C. The patient who falls: "It's always a trade-off". JAMA. 2010 Jan;303(3):258-66.

10 Minneci C, Mello AM, Mossello E, Baldasseroni S, Macchi L, Cipolletti S, et al. Comparative study of four physical performance measures as predictors of death, incident disability, and falls in unselected older persons: the insufficienza Cardiaca negli Anziani Residenti a Dicomano Study. J Am Geriatr Soc. 2015 Jan;63(1):136-41.

11 Ward RE, Leveille SG, Beauchamp MK, Travison T, Alexander N, Jette AM, et al. Functional performance as a predictor of injurious falls in older adults. J Am Geriatr Soc. 2015 Feb;63(2):315-20.

12 Delbaere K, Kochan NA, Close JC, Menant JC, Sturnieks DL, Brodaty H, et al. Mild cognitive impairment as a predictor of falls in community-dwelling older people. Am J Geriatr Psychiatry. 2012 Oct;20(10):845-53.

13 Muir SW, Gopaul K, Montero Odasso MM. The role of cognitive impairment in fall risk among older adults: a systematic review and meta-analysis. Age Ageing. 2012 May;41(3):299-308.
14 Bohannon RW, Tudini F. Unipedal balance test for older adults: a systematic review and meta-analysis of studies providing normative data. Physiotherapy. 2018 Dec;104(4):37682.

15 Herman T, Mirelman A, Giladi N, Schweiger A, Hausdorff JM. Executive control deficits as a prodrome to falls in healthy older adults: a prospective study linking thinking, walking, and falling. J Gerontol A Biol Sci Med Sci. 2010 Oct; 65(10):1086-92.

16 Welmerink DB, Longstreth WT Jr, Lyles MF, Fitzpatrick AL. Cognition and the risk of hospitalization for serious falls in the elderly: results from the Cardiovascular Health Study. J Gerontol A Biol Sci Med Sci. 2010 Nov;65(11):1242-9.

17 Kearney FC, Harwood RH, Gladman JR, Lincoln N, Masud T. The relationship between executive function and falls and gait abnormalities in older adults: a systematic review. Dement Geriatr Cogn Disord. 2013;36(12):20-35.

18 Hsu CL, Nagamatsu LS, Davis JC, Liu-Ambrose T. Examining the relationship between specific cognitive processes and falls risk in older adults: a systematic review. Osteoporos Int. 2012 Oct;23(10):2409-24.

19 Montero-Odasso M, Verghese J, Beauchet O, Hausdorff JM. Gait and cognition: a complementary approach to understanding brain function and the risk of falling. J Am Geriatr Soc. 2012 Nov;60(11):2127-36. 
20 Meguro K, Ishii H, Yamaguchi S, Ishizaki J, Shimada M, Sato M, et al. Prevalence of dementia and dementing diseases in Japan: the Tajiri project. Arch Neurol. 2002 Jul;59(7):1109-14.

21 Meguro K, Ishii H, Yamaguchi S, Ishizaki J, Sato M, Hashimoto R, et al. Prevalence and cognitive performances of clinical dementia rating 0.5 and mild cognitive impairment in Japan. The Tajiri project. Alzheimer Dis Assoc Disord. 2004 Jan-Mar;18(1):3-10.

22 Vellas BJ, Wayne SJ, Romero L, Baumgartner RN, Rubenstein LZ, Garry PJ. One-leg balance is an important predictor of injurious falls in older persons. J Am Geriatr Soc. 1997 Jun;45(6):735-8.

23 Lundin H, Sääf M, Strender LE, Nyren S, Johansson SE, Salminen H. One-leg standing time and hip-fracture prediction. Osteoporos Int. 2014 Apr;25(4):1305-11.

24 Gehlsen GM, Whaley MH. Falls in the elderly: part II, Balance, strength, and flexibility. Arch Phys Med Rehabil. 1990 Sep;71(10):739-41.

25 Vellas BJ, Wayne SJ, Garry PJ, Baumgartner RN. A two-year longitudinal study of falls in 482 community-dwelling elderly adults. J Gerontol A Biol Sci Med Sci. 1998 Jul;53(4):M264-74.

26 Tinetti ME, Speechley M, Ginter SF. Risk factors for falls among elderly persons living in the community. N Engl J Med. 1988 Dec;319(26):1701-7.
27 Rubenstein LZ, Josephson KR, Trueblood PR, Loy S, Harker JO, Pietruszka FM, et al. Effects of a group exercise program on strength, mobility, and falls among fall-prone elderly men. J Gerontol A Biol Sci Med Sci. 2000 Jun;55(6):M317-21.

28 Buatois S, Perret-Guillaume C, Gueguen R, Miget P, Vançon G, Perrin P, et al. A simple clinical scale to stratify risk of recurrent falls in community-dwelling adults aged 65 years and older. Phys Ther. 2010 Apr;90(4):550-60.

29 Michikawa T, Nishiwaki Y, Takebayashi T, Toyama Y. One-leg standing test for elderly populations. JOrthop Sci.2009Sep;14(5):67585.

30 Netz Y, Argov E. Assessment of functional fitness among independent older adults: a preliminary report. Percept Mot Skills. 1997 Jun;84(3 Pt 1):1059-74.

31 Briggs RC, Gossman MR, Birch R, Drews JE, Shaddeau SA. Balance performance among noninstitutionalized elderly women. Phys Ther. 1989 Sep;69(9):748-56.

32 Hurvitz EA, Richardson JK, Werner RA, Ruhl AM, Dixon MR. Unipedal stance testing as an indicator of fall risk among older outpatients. Arch Phys Med Rehabil. 2000 May;81(5):58791.

33 Goto S, Sasaki A, Takahashi I, Mitsuhashi Y, Nakaji S, Matsubara A. Relationship between cognitive function and balance in a community-dwelling population in Japan. Acta Otolaryngol. 2018 May;138(5):471-4.
34 Arai T, Fujita H, Maruya K, Morita Y, Asahi $\mathrm{R}$, Ishibashi $\mathrm{H}$. The one-leg portion of the Stand-Up Test predicts fall risk in aged individuals: A prospective cohort study. J Orthop Sci. 2020 Jul;25(4):688-92.

35 Bohannon RW. Single limb stance times: a descriptive meta-analysis of data from individuals at least 60 years of age. Top Geriatr Rehabil. 2006;22(1):70-7.

36 Lichtenstein MJ, Burger MC, Shields SL, Shiavi RG. Comparison of biomechanics platform measures of balance and videotaped measures of gait with a clinical mobility scale in elderly women. J Gerontol. 1990 Mar;45(2):M49-54.

37 Macrae PG, Lacourse M, Moldavon R. Physical performance measures that predict faller status in community-dwelling older adults. J Orthop Sports Phys Ther. 1992;16(3):123-8.

38 Ory MG, Schechtman KB, Miller JP, Hadley EC, Fiatarone MA, Province MA, et al. Frailty and injuries in later life: the FICSIT trials. J Am Geriatr Soc. 1993 Mar;41(3):283-96.

39 Kumai K, Nakamura K, Meguro K. Improved learning of sequential behaviour during cane gait training or stair climbing after femoral neck fracture: an implication for donepezil for very mild Alzheimer's disease. Psychogeriatrics. 2017 Mar;17(2):144-5. 